\title{
Predicting fluid pressure in sedimentary basins from seismic tomography
}

\author{
Brian M. O’Reilly, ${ }^{1,2}$ Manel Prada, ${ }^{1,2}$ François Lavoué ${ }^{1,2}$ and Sergei Lebedev ${ }^{1,2}$ \\ ${ }^{1}$ Dublin Institute for Advanced Studies, Geophysics Section, 5 Merrion Square, Dublin 2, Ireland.E-mail: bor@cp.dias.ie \\ ${ }^{2}$ Irish Centre for Research in Applied Geosciences, University College, Belfield, Dublin 4, Ireland
}

Accepted 2019 August 15. Received 2019 August 14; in original form 2019 February 15

\begin{abstract}
SUMMAR Y
Gravitational compaction of thick $(2-10 \mathrm{~km})$ sediment accumulations in sedimentary basins is controlled by the interplay of mechanical and chemical processes that operate over many orders of magnitude in spatial scale. The compaction of sediments into rock typically involves a density increase of $\approx 500$ to $1000 \mathrm{~kg} \mathrm{~m}^{-3}$, occurring over a depth-scale of several kilometres. The volume decrease in the compacting sediments releases vast volumes of water, which plays an important part in the global hydrological cycle and also in tectonic and geochemical processes; including the formation of hydrocarbon and mineral deposits. This study utilizes recently developed tomographic seismic images from the Porcupine Basin, which lies in the deep-water North Atlantic Ocean. A generic method for predicting fluid pressure variations that are driven by gravitational compaction is developed over the scale of the entire sedimentary basin. The methodology is grounded upon both observational evidence and empirically based theories, relying on geophysical measurements and relationships between sediment porosities and densities. The method is based upon physical concepts that are widely used in the petroleum industry and applied extensively in models of overpressure development in sedimentary basins. Geological and geophysical data from exploration wells are used to test the predictions of the method at two locations within the basin and are found to be in good agreement with the theory.
\end{abstract}

Key words: Permeability and porosity; Europe; Seismic tomography; Sedimentary basin processes.

\section{IN TRODUCTION}

Recent advances in the acquisition of multichannel seismic (MCS) data sets using long offset streamers has permitted the development of detailed seismic velocity models of the structure of sedimentary basins. This paper uses results from a previous study in the Porcupine Basin (Prada et al. 2018) to develop a methodology for predicting pore pressure variations at a basin-wide scale $\left(10^{2} \mathrm{~km}\right)$ from such tomographic models. The methods developed are generic and applicable to a variety of tectonic settings, where gravitational compaction of sediments into solid rock is important.

The developed methodology is based upon early work on the petrophysical properties (i.e. seismic velocities and bulk density) and the mechanical behaviour of compacting sediments over vertical scales of several kilometres (Athy 1930; Wyllie et al. 1956, 1958; Ludwig et al. 1970; Brocher 2005). These earlier studies were based on an experimental and empirical approach.

Over basin-wide scales, the degree of fluid overpressure is controlled by the balance between the creation of pore pressure by sediment loading and its dissipation, controlled by sediment permeability (Hantschel \& Kauerauf 2009; Marín-Moreno et al. 2013a). This is ultimately related to the development and breaching of lithological permeability barriers during basin development and sedimentation (Osborne \& Swarbrick 1997; Swarbrick et al. 2002; Tingay et al. 2009; Prada et al. 2018).

The physical concepts used in this study are widely known and routinely applied in petroleum exploration and drilling technologies (Eaton 1975; Hantschel \& Kauerauf 2009). These older concepts and axioms are used to build a simple predictive model for basinwide variations in pore fluid pressure that is potentially testable with observational exploration borehole information.

More sophisticated geomechanical models that are constrained by seismic and exploration well data have been developed and applied to calculate overpressure due to disequilibrium compaction and thermal expansion in deep sedimentary basins, such as in the Black Sea Basin (Marín-Moreno et al. 2013b). The novelty of the simpler approach developed here lies in the use of high-resolution tomographic images of post-rift sedimentary seismic velocities for quantifying and predicting compaction and fluid pressure variations at the scale of an entire sedimentary basin.

The focus of this study is the Porcupine Basin, which lies in deep-water off the southwestern coast of Ireland (Fig. 1). This sedi- 


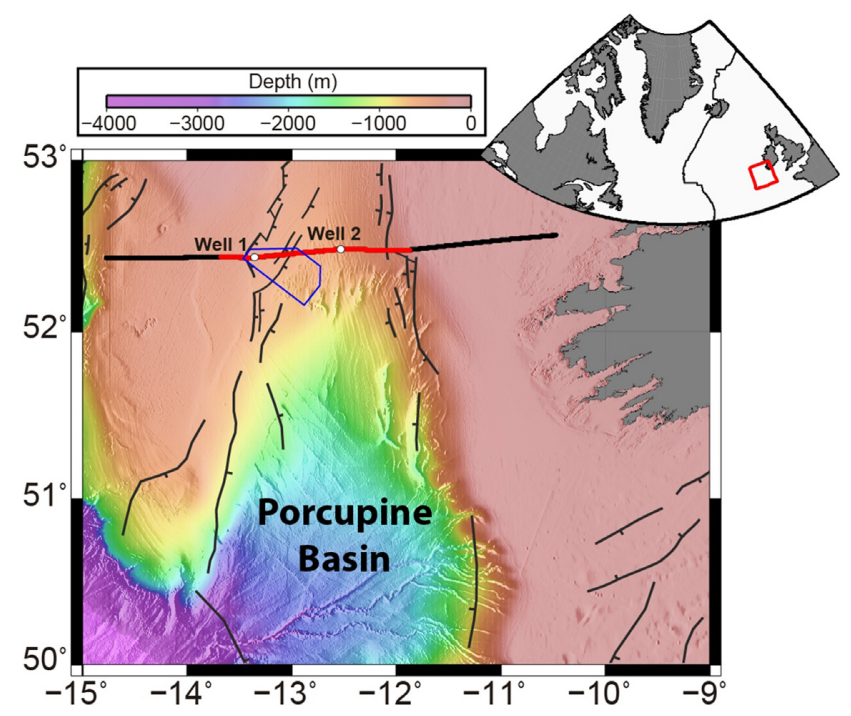

Figure 1. Bathymetry map of the Porcupine Basin showing the location of the MCS line used in this study (black line). Only shot gathers along the red section were included in the traveltime tomography. The white dots correspond to the two exploration wells used in this study. The blue outline around Well 1 indicates a region with 3-D seismic coverage. Bathymetry data set is extracted from Amante \& Ekins (2009). The location of the Mesozoic basement fault system is also shown.

mentary basin is investigated, given the recent results on long-offset streamer traveltime tomography of the post-rift sequence in the basin (Prada et al. 2018).

\section{THE PORCUPINE BASIN}

The Porcupine Basin formed in response to several rifting and subsidence phases during the Late Paleozoic to Cenozoic (Tate \& Dobson 1988; Moore 1992; Croker \& Shannon 1995; Naylor \& Shannon 2011). Tectonic extension in the basin led to a dramatic crustal thinning that increases from north to south (Reston et al. 2004; O'Reilly et al. 2006; Watremez et al. 2016; Prada et al. 2017; Chen et al. 2018). A significant post-rift phase of extensional faulting and reactivation of syn-rift faults occurred during the Mid-Late Eocene (Worthington \& Walsh 2016; Prada et al. 2018).

These recent results, based on the analysis of 2-D and 3-D MCS reflection data (Fig. 2a) revealed hitherto unrecognized phases of post-rift (i.e. Cretaceous and Cenozoic) normal faulting, which involved the reactivation of syn-rift faults. Palaeocene and Early Eocene sediments indicate an abrupt regression followed by regional subsidence from the Mid Eocene to Recent (McDonnell \& Shannon 2001; Jones et al. 2001). This coincides with the reactivation of syn-rift basin-bounding faults during the Mid-Late Eocene times (Worthington \& Walsh 2016).

Hemipelagic siliciclastic and calcareous sediments, interspersed with deep-water turbidite fan systems make up the predominant facies of this sediment-starved depositional environment. More details of the seismic stratigraphy and structural geology of the post-rift sequence (Fig. 2a) in the Porcupine Basin, relevant to the current paper, is given in Worthington \& Walsh (2016).

\section{Geophysical background}

A detailed $P$-wave velocity tomographic image (Fig. $2 \mathrm{~b}$ ) of the shallow post-rift structure of the northern Porcupine Basin has been derived using 10-km-long streamer data by Prada et al. (2018). This study demonstrated the application of quantitative seismic tomography of long-streamer controlled source data in providing insight into fluid and fault interaction within post-rift sedimentary systems. The results are particularly well constrained in three dimensions with the availability of a 3-D seismic data volume (blue polygon in Fig. 1), which samples the western basin-bounding fault zone and includes the seismic profile depicted in Fig. 2.

Prada et al. (2018) converted their seismic velocity model into density (Fig. 3a) using a velocity-density relationship derived from exploration wells in the area, providing estimates of the bulk sediment density (Fig. 3b). The vertical density and porosity variations, shown in Fig. 4, principally reflect the gravitational compaction of mud-prone sediments during burial. Lateral variations in velocity, density and porosity across the basin axis (Fig. 4) strongly correlate with a thicker Neogene and Quaternary post-rift sequence in the centre of the basin (Fig. 2).

These observations suggest fluid flow driven by differential compaction towards the margins of the basin with the western basinbounding fault acting as a natural hydraulic barrier, leading to fluid pressure buildup in the turbidite sand sequences (Prada et al. 2018). In this paper, this interpretation is tested quantitatively, by calculating predictions of pore fluid pressure that can be compared to legacy exploration borehole fluid pressure data.

\section{DENSITY AND SEISMIC VELOCITY}

Since the 1950s, empirical relationships between seismic velocities and densities of sediments have been developed in the context of marine geophysical studies of sedimentary basins (Nafe \& Drake 1957; Ludwig et al. 1970; Barton 1986) and hydrocarbon exploration (Gardner et al. 1974). A general review of these relationships with applications to seismic hazard assessment is given in Brocher (2005).

Empirical relationships between sediment densities $\left(\rho_{s}\right)$ and compressional wave velocities $\left(V_{p}\right)$ are usually cast in terms of polynomial functions of $V_{p}$. Examples are

$$
\begin{aligned}
\rho_{s}= & 1.6612 V_{p}-0.4721 V_{p}^{2}+0.0671 V_{p}^{3}-0.0043 V_{p}^{4} \\
& +0.000106 V_{p}^{5},
\end{aligned}
$$

- commonly known as the 'Nafe-Drake relationship' (Nafe \& Drake 1957; Brocher 2005) and meant to be comprehensive; including unconsolidated sediment suspensions - and

$\rho_{s}=1.74 V_{p}^{\frac{1}{4}}$,

—also commonly known as 'Gardner's rule' (Gardner et al. 1974) and intended to apply to seismic velocities in boreholes, measured below the 'mud line', where a solid and coherent sediment grain framework is present.

With the availability of high resolution sonic velocity and electron density measurements from deep exploration wells, empirical relationships of this form can be formulated specifically using geophysical well-log data from any sedimentary basin. An example is from Hughes et al. (1998):

$\rho_{s}=0.295+1.337 V_{p}-0.273 V_{p}^{2}+0.019 V_{p}^{3}$.

This was obtained for the Shetland-Faeroe Basin, using exploration well-log data of this type. The same approach to predict sediment densities from seismic velocities is used in this study. 

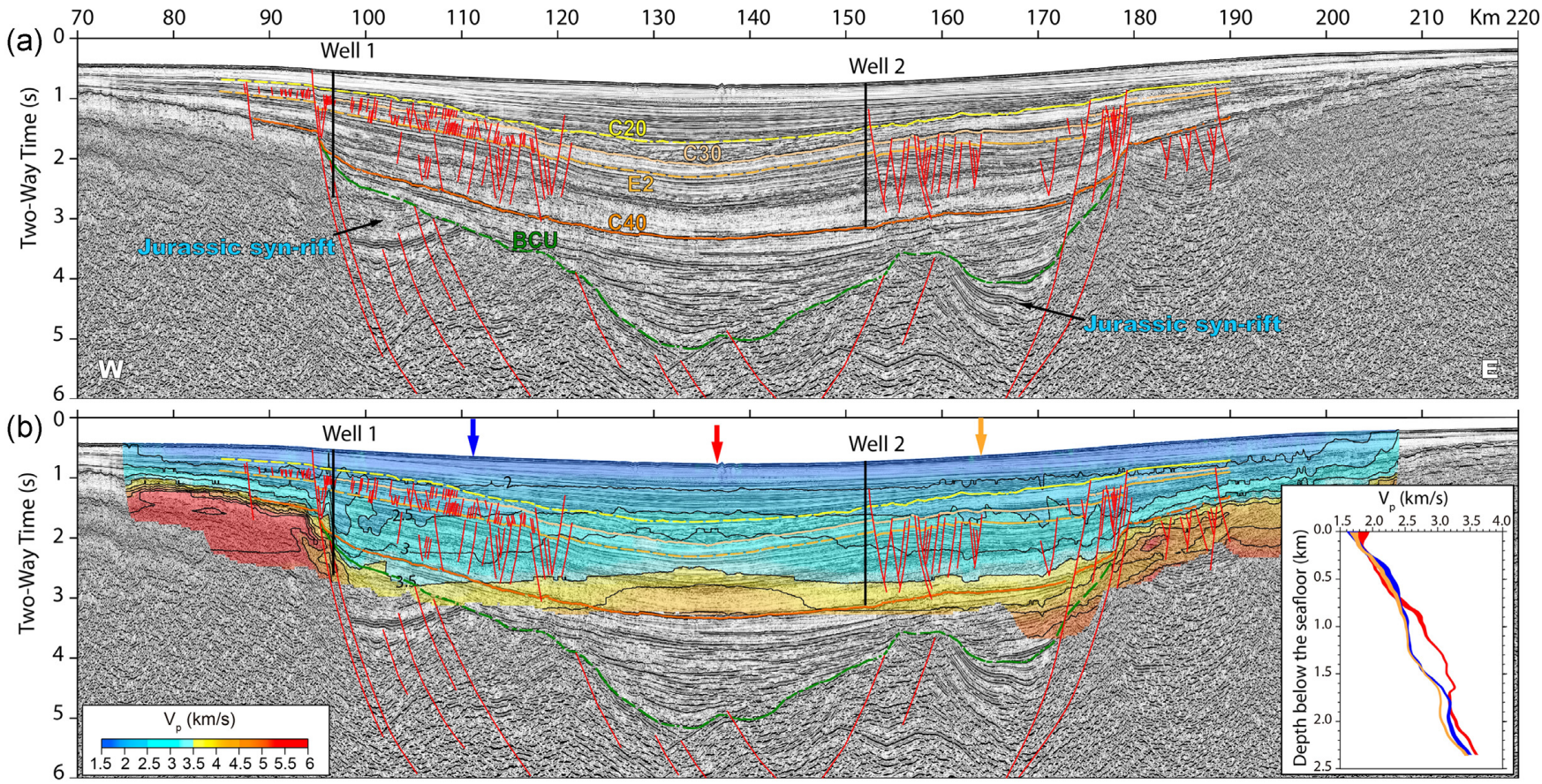

Figure 2. (a) Pre-stack time-migrated section showing the tectono-stratigraphic structure of the Porcupine Basin. Red lines are normal faults. Key horizons: C20, Early Miocene; C30, Late Eocene-Early Oligocene erosional surface; E2, Early-Mid Eocene; C40, base Cenozoic; BCU, Base Cretaceous Unconformity. The location of the two exploration wells is indicated as thick black lines. (b) Same seismic section combined with the tomographic model converted from depth to Two-Way-Time (TWT). Blue lines are iso-velocity contours of the $V_{p}$ model (in km s${ }^{-1}$ ). Thick blue, red and orange arrows depict the location of the velocity-depth profiles shown in the lowermost right corner of the seismic section. See Prada et al. (2018) for details.

\section{Application to the Porcupine Basin}

To calculate sediment densities, the bulk density and sonic log measurements from exploration wells (Fig. 1) were used to build the following polynomial $V_{p}-\rho_{s}$ relationship:

$\rho_{s}=0.357+1.114 V_{p}-0.182 V_{p}^{2}+0.010 V_{p}^{3}$.

This relationship, which fits the data with a correlation coefficient $R$ $\approx 0.86$, is valid for $V_{p}$ between 1.8 and $\sim 6 \mathrm{~km} \mathrm{~s}^{-1}$ (Fig. 3). See Prada et al. 2018, for more information on the methodology and model uncertainties. Moreover, the differences in the sediment densities that are obtained independently for eqs (3) and (4) are small (within 3 per cent). This provides supporting validation to the accuracy of the $V_{p}-\rho_{s}$ conversion, which is critical in the approach to fluid pressure estimation that is given later.

The 2-D density model resulting from the conversion of the $V_{p}$ model using eq. (4) (Fig. 4a) shows increasing density with depth in the basin from 1800 to $\sim 2400 \mathrm{~kg} \mathrm{~m}^{-3}$, while the base of the model displays densities of $\sim 2400$ to $2500 \mathrm{~kg} \mathrm{~m}^{-3}$.

Porosities $\phi_{s}$ across the Porcupine Basin are derived from the calculated density variations using the following standard expression given in Wyllie et al. $(1956,1958)$ :

$\phi_{s}=\frac{\rho_{m x}-\rho_{s}}{\rho_{m x}-\rho_{w}}$,

where $\rho_{m x}$ is the matrix or grain density, $\rho_{w}$ the density of the fluids occupying the pore space and $\rho_{s}$ the bulk sediment density. The result of this calculation is shown in Fig. 4(b). Porosity measurements from drill-core samples in Well 1 and Well 2 (Fig. 1) compare favourably with predictions (see Fig. 4b and Prada et al. 2018, for details).

\section{EQUATION OF SEDIMENT COMPACTION}

To derive pressure estimations, it is assumed that the general equation for the compaction of sediment of lithological/mineral composition $i$ at depth $h$ is given by,

$$
\frac{d\left(\rho_{s}-\rho_{o}\right)}{d h}=r_{i}\left(1-\frac{\rho_{s}-\rho_{o}}{\rho_{m x}-\rho_{o}}\right),
$$

where the variation of density with depth $d\left(\rho_{s}-\rho_{o}\right) / d h$ depends on the rate $r_{i}$ at which the sediment with initial density $\rho_{o}$ becomes compacted to bulk density $\rho_{s}$ due to lithostatic (overburden) pressure, as it is buried to greater depths. As porosity is lost, sediment is gradually transformed into rock due to both mechanical compaction and diagenetic-chemical effects, until its density approaches that of constituent rock matrix minerals $\rho_{m x}$.

Assuming a constant compaction rate $r_{i}$ at a point, the integration of this equation describes how density varies with depth for the lithology $i$ at that point in space:

$\rho_{s}=\rho_{o}+\left(\rho_{m x}-\rho_{o}\right)\left(1-e^{\frac{-r_{i}\left(h-h_{w}\right)}{\rho_{m x}-\rho_{o}}}\right)$.

This relationship describes a curve in which the density $\rho_{s}$ increases with depth $h$ towards the limiting asymptotic value $\rho_{m x}$ typical of metamorphic/igneous basement rock.

The value of the parameter $r_{i}$ gives the rate at which these processes occur and is most easily related to eq. (7) by taking its log-transform:

$\left|r_{i}\right|=\frac{\rho_{m x}-\rho_{o}}{h-h_{w}} \log _{e}\left(1-\frac{\rho_{s}-\rho_{o}}{\rho_{m x}-\rho_{o}}\right)$.

Thus, the compaction rate $r_{i}$ at any depth $h$ can be determined directly from eq. (8) once the density variations $\rho_{s}$ can be inferred 

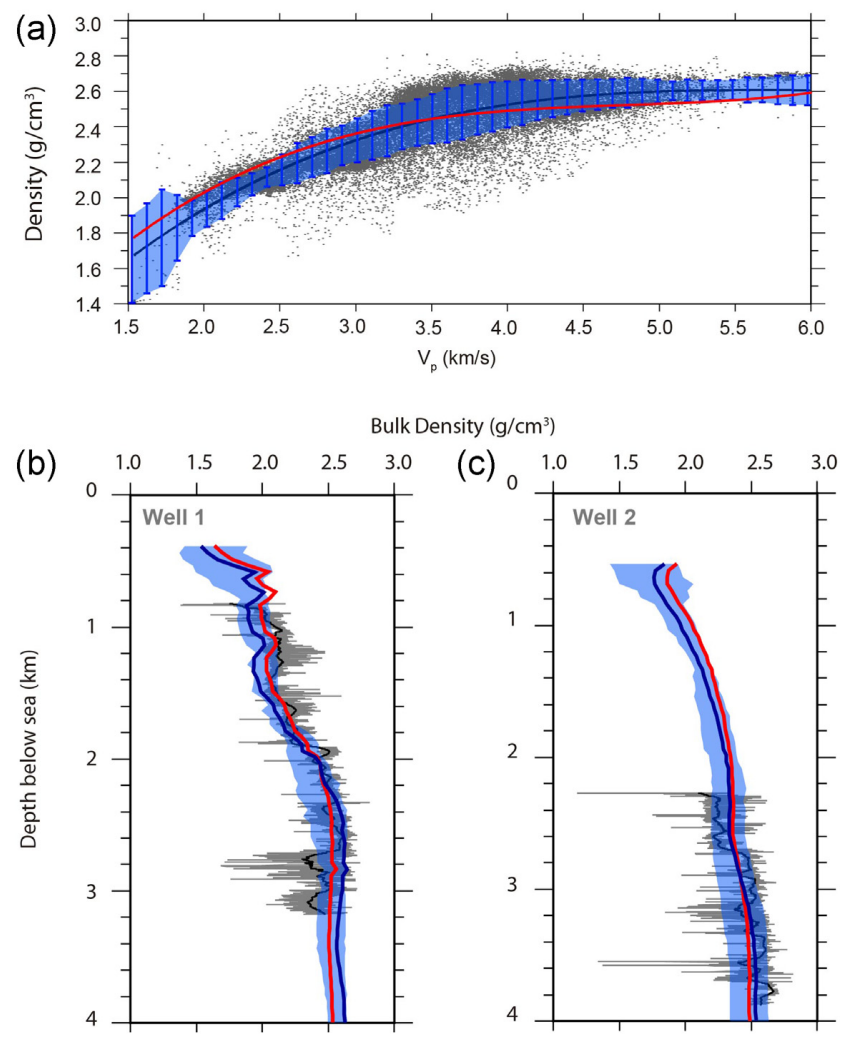

Figure 3. (a) Plot of sonic velocity and density borehole-log data from exploration wells presented in Prada et al. (2018), used to derive eq. (4). The blue band depicts the range of uncertainty of the polynomial relationship in eq. (4), attributed to the sparse distribution of samples. The red line is the polynomial relationship presented in Hughes et al. (1998). (b) Observed and predicted density variation in Well 1 using the $V_{p}-\rho_{s}$ calibration from Prada et al. (2018) (blue line), and from Hughes et al. (1998) (red line). The blue band depicts the degree of uncertainty derived from (a). (c) Corresponding observed and predicted densities for Well 2.

from seismic velocity measurements, using the empirical equations, described previously.

\section{Empirical constraints}

Eqs (6) and (7) imply a porosity-depth variation consistent with 'Athy's Law' (Athy 1930). Expressing $\rho_{o}$ and $\rho_{s}$ in terms of porosities $\left(\phi_{o}, \phi_{s}\right)$ and densities $\left(\rho_{w}, \rho_{m x}\right)$ yields,

$\rho_{s}=\rho_{m x}\left(1-\phi_{s}\right)+\rho_{w} \phi_{s}$

and

$\rho_{o}=\rho_{m x}\left(1-\phi_{o}\right)+\rho_{w} \phi_{o}$.

Substituting eqs (9) and (10) into (7) implies

$\phi_{s}=\phi_{o} e^{\frac{-r_{i}(h-h w)}{\left(\rho_{m x}-\rho_{o}\right)}}$,

which is 'Athy's Law'.

Over the depth range considered in this case (up to $3.5 \mathrm{~km}$, see Fig. 3) eq. (7) describes the pathway by which density changes from $\rho_{o}$ to $\rho_{m x}$ for lithology $i$ with increasing depth. An individual sediment lithology, at any point in space, may be characterised by a distinct $\left(\rho_{m x}, \rho_{o}\right)$ couplet and a diagnostic $\left(\rho_{m x}, \rho_{o}, r_{i}\right)$ triplet that determines its response to gravitational compaction.
The values of these parameters, which are widely used in studies of sedimentary basin subsidence (Steckler \& Watts 1978; Sclater \& Christie 1980; Kominz et al. 2016) may be highly correlated for a given sediment particle size and composition. There is however limited observational data to substantiate this or to resolve possible patterns (Kominz et al. 2011). Table 1 lists the parameter definitions used throughout this paper with their physical dimensions, while Fig. 5 defines these in space.

\section{FLUID PRESSURE VARIATIONS}

In the simple case of a gravitationally compacting sedimentary column that is in ideal hydrostatic equilibrium, the pore fluid pressure $P_{f}$ of the sediments at depth $h$ equals the hydrostatic pressure $P_{h}$ and is defined as:

$P_{f}=P_{h}=\rho_{w} g h$,

with $g=9.81 \mathrm{~m} \mathrm{~s}^{-2}$ the gravitational acceleration and $\rho_{w}$ the fluid density in the sediment pore spaces $\left(\rho_{w} \approx 1030 \mathrm{~kg} \mathrm{~m}^{-3}\right.$ for seawater).

The corresponding lithostatic pressure at depth $h$ is given by the integral of the density distribution over the depth from the sea surface into the sedimentary column:

$P_{l}=\rho_{w} g h_{w}+\int_{h_{w}}^{h} \rho_{s} g d h$,

$\rho_{s}$ is defined by eq. (7) and $h_{w}$ is the ocean depth (Fig. 4). Substituting eqs (7) into (13) and assuming a constant rate $r_{i}=r_{a m b}$ throughout the sedimentary column yields the lithostatic pressure for a sedimentary sequence in hydrostatic equilibrium:

$P_{l}=\rho_{w} g h_{w}+\rho_{m x} g\left(h-h_{w}\right)-\frac{\left(\rho_{m x}-\rho_{o}\right) g}{R_{a m b}}\left(1-e^{-R_{a m b}\left(h-h_{w}\right)}\right)$,

where $R_{a m b}=r_{a m b} /\left(\rho_{m x}-\rho_{o}\right)$ is the ambient porosity decay rate [equivalent to the compaction parameter $(c)$ as defined in Sclater \& Christie (1980)] for a column in perfect equilibrium (see Table 1 for parameter definitions). The equilibrium state (i.e. $R_{i}=R_{a m b}$ everywhere in a hypothetical simple system) is reached when fluid pressure gradients decay, such that the fluid flux approaches zero over long geological timescales.

\section{The non-equilibrium state}

Where a sedimentary column is not in a state of ideal hydraulic equilibrium at any depth, the fluid pressure $P_{f}$ must lie somewhere between $P_{h}$ and $P_{l}$. The variation in $P_{f}$ is computed from the spatial variations in the 'observed' values of $R_{i}$ (Fig. 5) with respect to the equilibrium hydrostatic value $\left(R_{a m b}\right)$. The equilibrium value may show some dependence on sediment lithology: but this is unclear when considering the published compilations of the key parameters involved (Kominz et al. 2011, and Table 2).

In this case the fluid pressure (for the non-equilibrium state) with respect to the hydrostatic pressure at depth $h$ is given by:

$P_{f}=\rho_{w} g h+\left(h-h_{w}\right)\left(\rho_{s a v}-\rho_{w}\right) g\left(\frac{e^{R_{a m b}\left(h-h_{w}\right)}-e^{R_{i}\left(h-h_{w}\right)}}{e^{\left(R_{a m b}+R_{i}\right)\left(h-h_{w}\right)}}\right)$, 


\section{Distance $(\mathrm{km})$}

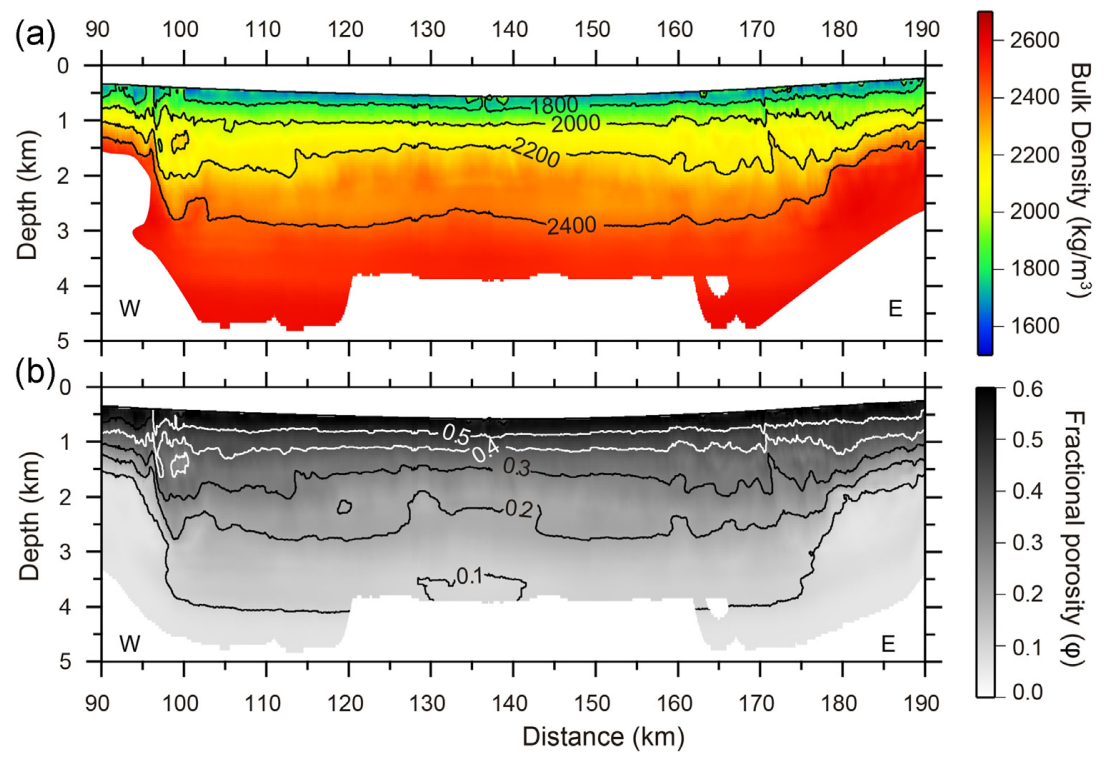

Figure 4. (a) Bulk 2-D density model derived from the tomographic $V_{p}$ model (Fig. 2) using eq. (4). (b) Fractional porosity across the Porcupine Basin derived form the bulk density model using eq. (5). Modified from Prada et al. (2018).

Table 1. List of parameter definitions with their SI units.

- $h_{w}$ - ocean water depth (m)

- $h$ - depth below sea surface (m)

- $g$ - gravitational acceleration $\left(9.81 \mathrm{~m} \mathrm{~s}^{-2}\right)$

- $\rho_{w}$-fluid density $\left(\mathrm{kg} \mathrm{m}^{-3}\right)$

- $\rho_{m x}$-solid grain density $\left(\mathrm{kg} \mathrm{m}^{-3}\right)$

- $\rho_{o}$-initial sediment density $\left(\mathrm{kg} \mathrm{m}^{-3}\right)$

- $\rho_{s}$-sediment density at depth $h\left(\mathrm{~kg} \mathrm{~m}^{-3}\right)$

- $\phi_{o}$-initial sediment porosity (dimensionless) $\bullet \phi_{s}-$ sediment porosity at depth $(h)$ (dimensionless)

- $r_{i}$ - sediment density decay rate of lithology $(i)\left(\mathrm{kg} \mathrm{m}^{-4}\right)$

- $r_{a m b}$ - ambient equilibrium sediment density decay rate of lithology $i\left(\mathrm{~kg} \mathrm{~m}^{-4}\right)-\left(r_{a m b} \geq r_{i}\right)$

- $R_{i}$ - sediment porosity decay rate of lithology $(i)\left(\mathrm{m}^{-1}\right)-R_{i}=\frac{r_{i}}{\left(\rho_{m x}-\rho_{o}\right)} \bullet R_{a m b}-$ ambient equilibrium sediment porosity decay rate of lithology $i\left(\mathrm{~m}^{-1}\right)-$

$R_{a m b}=\frac{r_{a m b}}{\left(\rho_{m x}-\rho_{o}\right)}-\left(R_{a m b} \geq R_{i}\right)$

- $P_{h}$-hydrostatic pressure MPa $\left(\mathrm{kg} \mathrm{m}^{-1} s^{-1}\right)$

- $P_{l}$-lithostatic pressure $\mathrm{MPa}\left(\mathrm{kg} \mathrm{m}^{-1} s^{-1}\right)$

- $P_{f}$-fluid pressure MPa $\left(\mathrm{kg} \mathrm{m}^{-1} s^{-1}\right)$

where the average density $\rho_{\text {sav }}$ is determined by integration of eq. (7):

$$
\rho_{s a v}=\rho_{m x}-\left(\rho_{m x}-\rho_{o}\right) \frac{1-e^{-R_{a m b}\left(h-h_{w}\right)}}{R_{a m b}\left(h-h_{w}\right)} .
$$

Eq. (15) is fundamental to the fluid pressure calculations presented here.

It implies that where $R_{i}$ approaches $R_{a m b}$ the fluid pressure approaches the hydrostatic value $\left(P_{f} \rightarrow P_{h}=\rho_{w} g h\right)$. The condition $R_{i} \rightarrow 0$ as $h \rightarrow \infty$ becomes physically untenable, since the pore fluid overpressure eventually exceeds the strength of the compacting rock; leading to mechanical instability and fracturing, causing fluid pressure dissipation and a return to the equilibrium state.

The second term in eq. (15) gives the 'kick' in the hydrostatic pressure defined by the increase $\Delta P_{f}$ associated with the change $\Delta R=R_{a m b}-R_{i}$, at depth $h$. Regions within the sedimentary basin where the sediments are significantly overpressured will be defined by low values of $R_{i}$.

\section{THE APPLICATION OF THE METHOD}

The application of the theory and method, given in the previous sections, first involves the use of eq. (8) for determining the distribution of $R_{i}$ values across the tomographic models of physical parameters, derived for the Porcupine Basin (Figs 2 and 4). In order to apply this equation, $\rho_{m x}$ and $\rho_{0}$ are set equal to 2710 and $1710 \mathrm{~kg} \mathrm{~m}^{-3}$, respectively, so that $\left(\rho_{m x}-\rho_{o}\right)=1000 \mathrm{~kg} \mathrm{~m}^{-3}$. This is in agreement with global observations from deep-sea mud rich sediments (see next section). The result of this calculation is given in Fig. 6.

Beneath the first $500 \mathrm{~m}$ of sediments, the value $R_{i}$ shows little variation near the basin centre, suggesting that the sediments are near a state of hydrostatic equilibrium in this region; a state that is consistent with low rates of sedimentation during Neogene times (above the Early to Mid Eocene surface (C30) in Fig. 2). The lowest values of $R_{i}$ are restricted to the eastern and western margin of the basin (at 95-110 and 160-180 km distance; Fig. 6), where it has been proposed that Recent Cenozoic faulting is related to overpressured zones (Prada et al. 2018). 


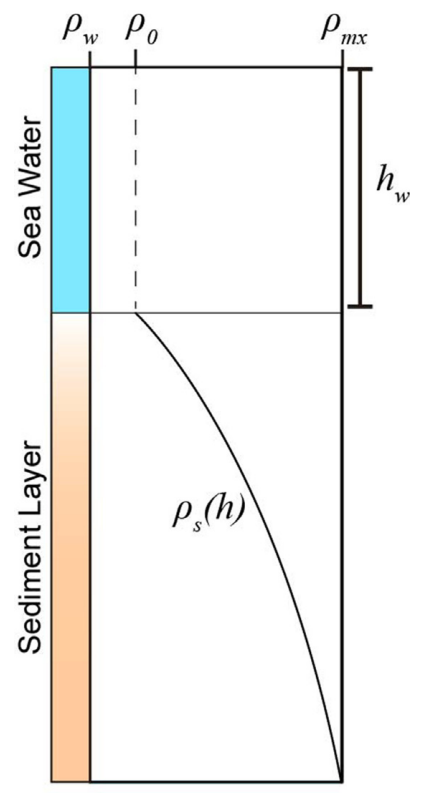

Figure 5. Simple 1-D sketch showing the parameter definitions used in the physical model for gravitational compaction and hydrostatic pressure variation. $h_{w}$ - ocean water depth, $h$ - depth measured from ocean surface, $\rho_{w}$ - seawater density, $\rho_{o}$ - initial sediment density (density of seabed sediments), $\rho_{s}$ - sediment density at any depth $h, \rho_{m x}$ - sediment grain density (asymptotic density limit).

\section{Defining the equilibrium value $\left(R_{a m b}\right)$}

The ambient value $R_{a m b}$ is defined by the depth distribution of those $R_{i}$ values within the centre of the basin (between 120 and $150 \mathrm{~km}$ of distance), where no observable normal faulting influences the tomographic results (Fig. 2) and sediments are likely near to a state of hydrostatic equillibrium. The depth distribution of $R_{i}$ in Fig. 7 depicts an increase of $R_{i}$ with depth down to $1.25 \mathrm{~km}$ beneath the seabed, where the value stabilises at a maximum value close to $0.60 \times 10^{-3} \mathrm{~m}^{-1}$

At near ocean floor depths $(0-400 \mathrm{~m}), R_{a m b}<0.4 \times 10^{-3} \mathrm{~m}^{-1}$. These low apparent values may relate to a mechanical coupling between the formidable ocean-storm swell and the sediments on the ocean floor, which is related to the very frequent North Atlantic Ocean storms and hurricanes. This aspect is beyond the scope of the current paper; but this possibility will be considered elsewhere.

Based on these considerations and upon the results given in Prada et al. (2018), we estimate $R_{a m b}=0.60 \pm 0.02 \times 10^{-3} \mathrm{~m}^{-1}$, with $\rho_{m x}=2710 \mathrm{~kg} \mathrm{~m}^{-3}$ and $\rho_{o}=1710 \mathrm{~kg} \mathrm{~m}^{-3}$. While $\rho_{o}$ agrees with a recent global compilation of bulk density measurements of deepwater seafloor sediments from Deep Sea Drilling Project (DSDP) boreholes (Tenzer \& Gladkikh 2014); $\rho_{m x}$ is consistent with the abundance of mud-prone sediments in the Porcupine Basin (McDonnell \& Shannon 2001) and also with the available petrophysical data (Prada et al. 2018) from the Porcupine Basin.

An important compilation from Ocean Drilling Project (ODP) data for the decay rates of surface porosity values from mud dominated clay sized clastic sediments between 175 and $1800 \mathrm{~m}$ burial depth (Kominz et al. 2011, 2016), independently yields $R_{i}=0.598$ $\times 10^{-3} \mathrm{~m}^{-1}$. This value lies exactly within our statistically determined value (Table 2 and Fig. 7). It is also close to the value obtained for a subset of 'mixed data' over the same depth inter$\operatorname{val}\left(R_{i}=0.675 \times 10^{-3} \mathrm{~m}^{-1}\right)$; but this estimate comprises a larger sample number, with more varied lithological composition (see Table 2).

\section{PREDICTED FLUID PRESSURE VARIATIONS}

The predicted fluid pressure $\left(P_{f}\right)$ variations across the Porcupine Basin are shown in Fig. 8, both as absolute pressures (Fig. 8a) and the overpressure component (Fig. 8b). Significant overpressure magnitudes on the western margin of the basin (up to $5 \mathrm{MPa}$ ) corresponds to the low-velocity zone found by Prada et al. (2018).

Down-hole pressure measurements for the deep exploration boreholes (Wells 1 and 2 in Fig. 1) permit predictions to be tested against observations at two localities along the pressure model. Pressures were calculated from drilling mud specific gravity measurements obtained from well completion reports (yellow dots in Fig. 9). This information was provided by the Petroleum Affairs Division of the Department of Communications, Climate Action and Environment of Ireland; www.pad.gov.ie.

Measured pressure variations with depth in the exploration boreholes are generally predicted by the theoretical ones. For example, the value obtained at $1350 \mathrm{~m}$ is in very good agreement with the predicted value (Fig. 9a). A broad overpressured zone between 600 and $1500 \mathrm{~m}$ also corresponds closely to the stratigraphic interval, composed of Early to Mid Eocene turbidite sands, interbedded with deep-water mudstones.

These predictions support a fluid flow model for the Porcupine Basin, based on the earlier seismic observations (see fig. 12 in Prada et al. 2018) that suggested higher overpressured regions along the basin margins, related to gravitational compaction. The quantitative predictions of the current study confirms this earlier geological interpretation.

\section{DISCUSSION}

According to eq. (15) fluid overpressure depends solely on the decrease in the compaction factors $\left(R_{i}\right)$ relative to an ideal ambient equilibrium value $\left(R_{a m b}\right)$ that is characteristic of lithology $(i)$. The measured pressures encountered in the two exploration boreholes are in agreement with the modest predicted pressures $(\approx 5$ $\mathrm{MPa}$ ): the highest overpressured region occurring along the margins of the Porcupine Basin (Fig. 8), associated with normal fault re-activation (Prada et al. (2018). Across the central region of the basin the fluid overpressure is low; consistent with gravitationally driven fluid flow towards the basin margins along high permeability sand-rich turbidite layers (Worthington \& Walsh 2016).

\section{Calibration and independent measures}

The equilibrium value of this parameter $\left(R_{a m b}\right)$ derived with the method presented (Fig. 7) is identical to measurements from lithologically similar deep-sea sediments from ODP boreholes (Kominz et al. 2011). These sediment samples (Table 2) come from the same depth range as the resolution depth of the tomographic model (Fig. 2) and the parameters have been directly measured from sediments of similar sediment particle size and composition to those encountered in the exploration wells.

These observations suggest that the methodology used in this work measures $R_{a m b}$ on a basin-wide scale, where significant variation in bulk sediment properties (either inherent or due to chemi$\mathrm{cal} /$ diagenetic effects) is not important in defining it. This parameter, 
Table 2. Sediment compaction parameters.

\begin{tabular}{lccc}
\hline Sediment particle size & $\phi_{o}$ (initial porosity) & $R_{i}$ (decay rate) & $N$ \\
\hline Clay/mud $(175$ to $\approx 1800 \mathrm{~m})$ & 0.614 & 0.598 & 71 \\
mixed data $(150$ to $\approx 1800 \mathrm{~m})$ & 0.614 & 0.675 & 2463
\end{tabular}

Compaction parameters for clay and mixed sediment particle sizes measured and derived by Kominz et al. (2011) from a comprehensive compilation of ODP data. Data taken from Tables 3 and 4 in this publication with sample depths indicated. Depth range overlaps the resolution depth of the tomographic imaging technique used in this study (see Fig. 2 and Prada et al. 2018). $N$ is the number of samples used to determine these parameters. The 'mixed data' subset of samples comprise the entire range of biogenic and siliciclastic sediments. See Kominz et al. (2011) and Kominz et al. (2016) for details on statistics. Units: $R_{i} \times 10^{3} \mathrm{~m}^{-1}$.

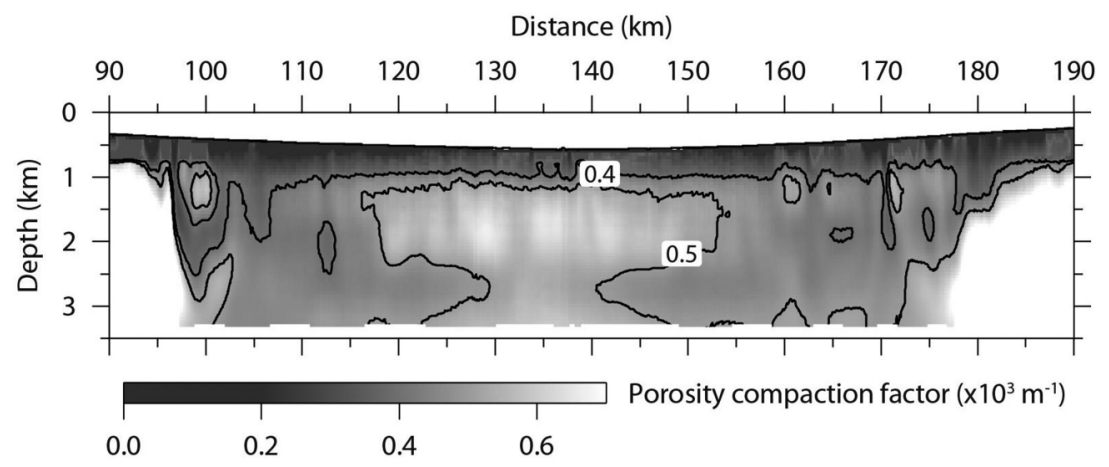

Figure 6. Variation in the calculated value of $R_{i}$ across the Porcupine Basin derived from eq. (8). Note, that $R_{i}$ shows less variation across the basin centre suggesting that the sediments are in a state near to hydrostatic equilibrium. Units: $R_{i} \times 10^{3} \mathrm{~m}^{-1}$.

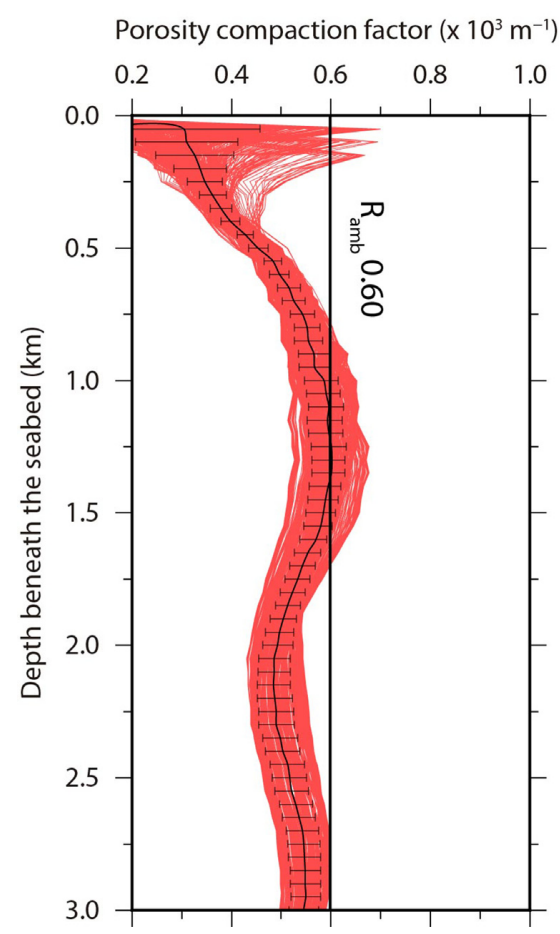

Figure 7. 1-D depth distributions of $R_{i}$ values across the centre $(120-150 \mathrm{~km}$ of distance) of the Porcupine Basin (red profiles). Black line and error bars correspond to the average of the distribution and its standard deviation at each depth. The solid vertical line corresponds to $R_{a m b}=0.6$, used in the overpressure calculations. Units: $R_{a m b} \times 10^{3} \mathrm{~m}^{-1}$. which is equivalent to the compaction parameter $(c)$ - as defined by Sclater \& Christie (1980)- is essential in reconstructions of sedimentary basin subsidence; particularly in passive continental margin settings in the North Atlantic region (e.g. Kominz et al. 2016), where some of the earliest such studies were undertaken (Steckler \& Watts 1978).

A key step in the pressure calculation (eq. 15) is the conversion of seismic $P$-wave velocities to bulk sediment densities. The relationship used to obtain this calibration (eq. 4) comes from the same exploration wells used to test the predicted fluid pressures. This means that the $V_{p}-\rho_{s}$ calibration and the measured pressures may not strictly be statistically independent.

However, eq. (3) was obtained independently by Hughes et al. (1998) from the Shetland-Faeroe Basin, where the geological setting and starved Cenozoic depositional environment are very similar to the Porcupine Basin. This equation yields an indistinguishable density distribution (Fig. 3) and hence leads to very similar predicted pressures. In this respect the calibration issue is not very significant in influencing the results presented in this study.

\section{The role of chemical processes}

Physical and chemical processes that accompany mechanical compaction are not explicitly included in the analysis: rather $R_{i}$ is implicitly regarded as a bulk parameter that includes these correlated processes over the depth range investigated (Fig. 2). The importance of these processes vary with chemical composition, depth of burial, temperature and fluid flow regime (Marín-Moreno et al. 2013b; Colombo et al. 2017). For example, the breakdown of feldspar into clay minerals is likely to be important in arkosic quartz-sand sediments and is sensitive to temperature and fluid flow. Diagenetic (or 

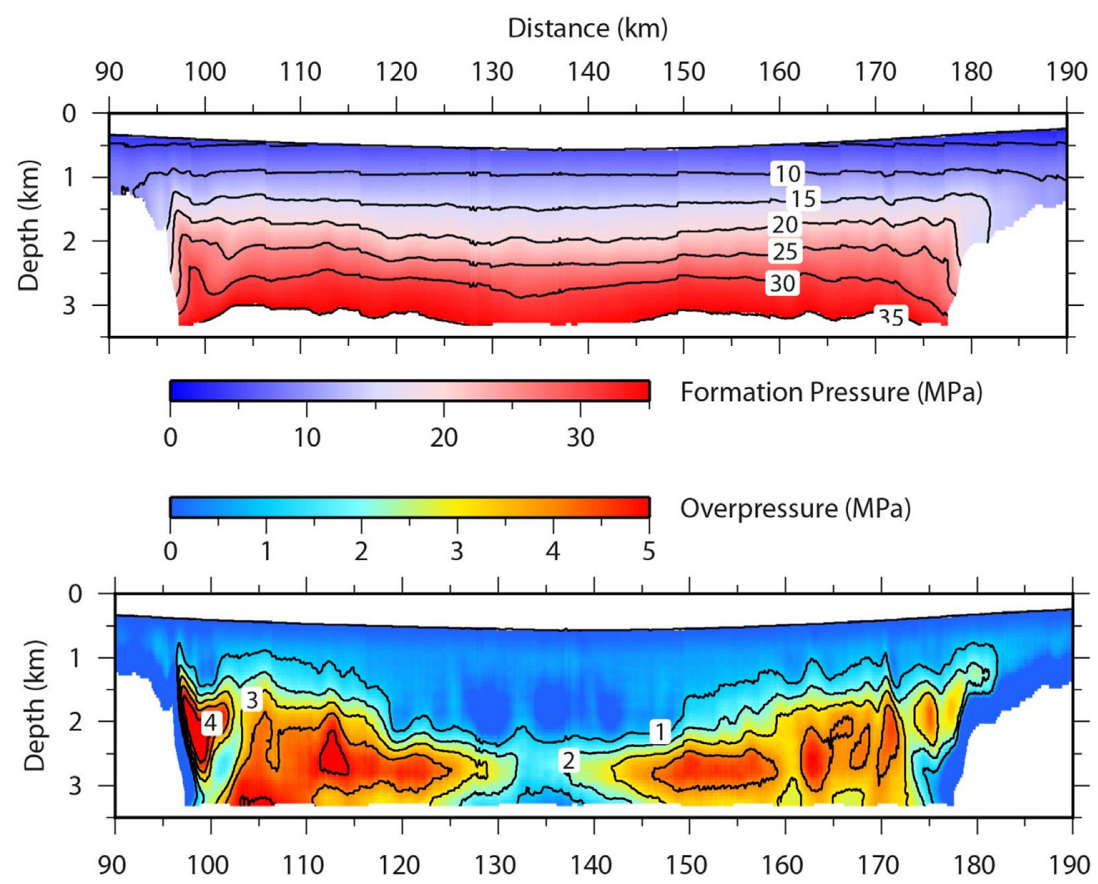

Figure 8. (a) Predicted fluid pressure $\left(P_{f}\right)$ variations across the Porcupine Basin. (b) Predicted overpressure $\left(\Delta P_{f}=P_{f}-P_{h}\right)$. Pressure variation is calculated from the values of $R_{i}$ across the basin depicted in Fig. 6, using eq. (15).
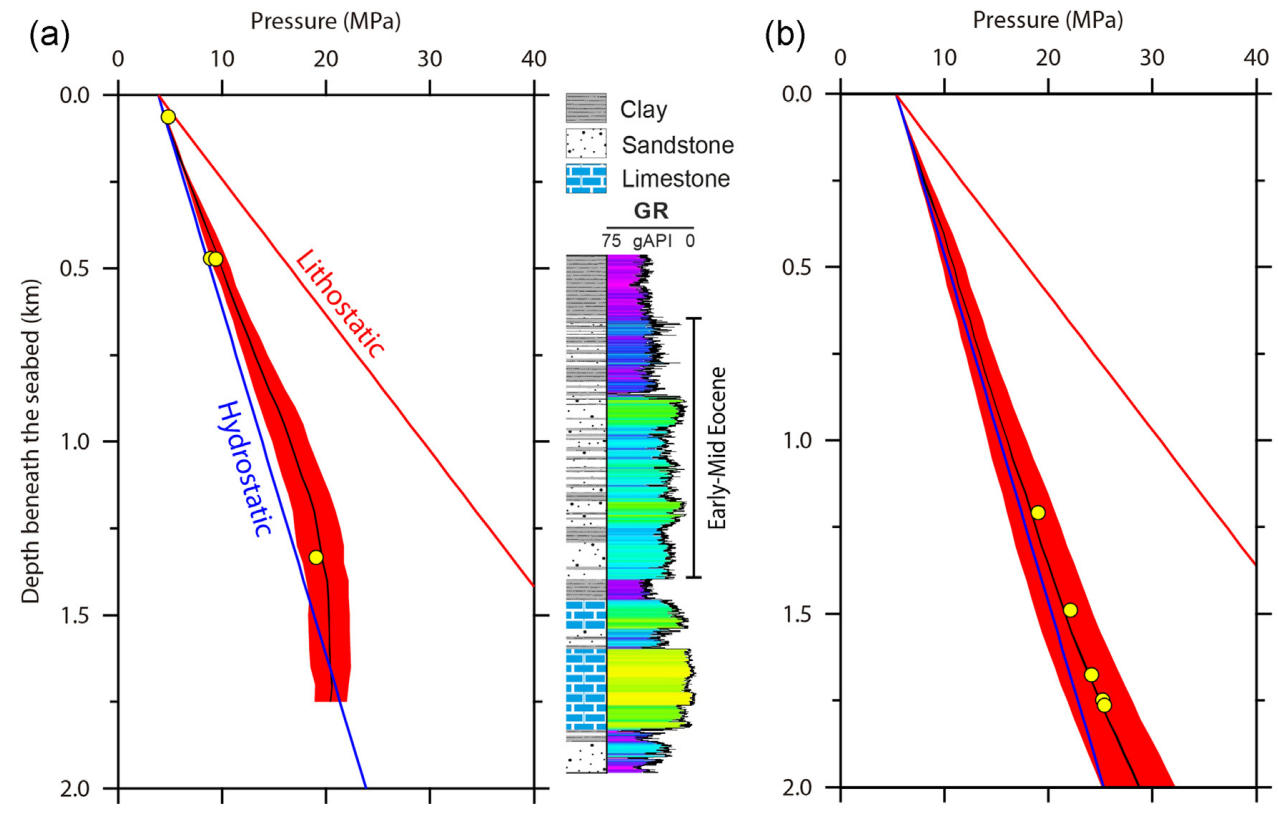

Figure 9. Measured versus predicted pressure variations in Wells 1(a) and 2(b). Blue and red lines indicate hydrostatic and lithostatic trends, respectively. Yellow dots represent downhole pressures calculated from drilling mud specific gravity measurements. Black lines indicate predicted pressures from eq. (15). Red shaded region represents the total error resulting from the uncertainty in the tomographic model of Prada et al. (2018). The lithological column for Well 1 depicts a clear depth correlation between overpressured areas and Early-Mid Eocene sandstones (GR stands for natural gamma ray log).

low grade metamorphic) changes in the polycyclic clay minerals of mud-prone sediments in deep-water oceanic basins (Goldstein et al. 1984) are controlled by the same factors.

In contrast, sand-prone sediments have very different mechanical properties and undergo pressure solution with burial and increasing vertical stresses. Pressure solution is a chemical process involving the diffusion of quartz into the interstitial pore spaces between sand grains. For pure, well sorted, sands the few measurements indicate the $R_{a m b} \approx 0-0.2 \times 10^{-3} \mathrm{~m}^{-1}$ over shallow depth ranges $(\leq 2 \mathrm{~km})$ with the initial sediment fractional framework porosities of $\approx 0.4$, consistent with grain framework structure (Kominz et al. 2011, and references therein).

The limited available compilations appear to suggest that sediments comprised of predominantly clay-sized particles have $R_{a m b}$ values close to $0.6 \times 10^{-3} \mathrm{~m}^{-1}$ (Kominz et al. 2011 and Table 2) over the depth, encountered in this study. This supports the notion that 
physico-chemical effects are of secondary importance in mud-prone sediment mixtures; that $R_{a m b}$ may be considered as a bulk statistical parameter and also that the change $\Delta R=R_{a m b}-R_{i}$ is principally due to fluid overpressure variation, caused by non-equilibrium compaction. The same is unlikely to be true at greater depths; as $\rho_{s} \rightarrow$ $\rho_{m x}$ (eq. 7) and chemical/diagenetic processes, driven by higher pressures and temperature, gradually become significant.

Numerical models that involve a complete inclusion and description of chemical and physical phenomena, such as coupled thermal and fluid flow processes have been developed and calibrated with exploration well and seismic data (Marín-Moreno et al., 2013b; Colombo et al. 2017). These models use empirical methods applied to wireline-logs such as Eaton's Method (Eaton 1975; van Ruth et al. 2004; Ramdhan \& Goulty 2018) to test model predictions, using advanced geophysical inversion techniques.

It would be interesting to apply these more sophisticated methods to test and compare with the simpler and more regional approach of the current study, which uses limited legacy exploration well data from the 1970s and 1980s. This requires a more rigorous study and analysis of specific, recently acquired, deep exploration well data from the Porcupine Basin. Such a study should include comprehensive pressure, temperature and petrological data, which are also colocated along the more recent long-streamer MCS lines in the basin (see -www.pad.gov.ie).

\section{CONCLUSIONS}

(1) The agreement between the predicted and the measured fluid pressures at different depths is good; and the modest $(\approx 5 \mathrm{MPa})$ elevated zones of overpressure are resolved in this case, along the marginal regions of the Porcupine Basin. Overpressure in the central region of the basin is lower, suggesting gravitationally induced flow towards the margins, as inferred in previous studies.

(2) A very high degree of internal consistency exists in this relatively simple method to measure overpressure. The method is founded on similar sediment compaction concepts as those used in more sophisticated approaches. Empirically derived bulk density changes in sediments, which are central to the method are similar to those measured from sedimentary basins with a similar geological environment.

(3) The predicted value of the equilibrium compaction factor $R_{a m b}$ agrees with independent measures from deep-sea sediments, compiled from ODP archives. This implies that it may be a gross diagnostic of bulk lithology.

(4) Further work is required to refine and validate the simple regional approach of this study, using recent deep borehole exploration and MCS data gathered in the Porcupine Basin. This would permit the inclusion of thermal, chemical and fluid flow processes and the usage of modern geophysical inversion techniques.

\section{ACKNOWLEDGEMENTS}

This publication has emanated from research supported in part by a research grant from Science Foundation Ireland (SFI) under Grant Number 13/RC/2092 and is cofunded under the European Regional Development Fund and by PIPCO RSG and its member companies. Seismic and Well data were provided by the Petroleum Affairs Division of the Department of Communications, Climate Action and Environment, Ireland (www.pad.gov.ie). Generic Mapping Tools (Wessel \& Smith 1998) and Seismic Unix software package (Stockwell 1999) were used in the preparation of this manuscript.
Nick O'Neill and Michael Hanrahan are thanked for advice on the legacy exploration well pressure data. We thank the Editor Alexis Maineult, Giuliana Rossi and Hector Marín-Moreno for constructive comments and suggestions on the original manuscript. Hector Marín-Moreno is particularly thanked for sharing his knowledge of fluid overpressure in sedimentary basins and providing guidance towards some key references; thereby significantly improving the paper.

\section{REFERENCES}

Amante, C. \& Eakins, B.W., 2009. ETOPO1 1 Arc-Minute Global Relief Model: Procedures, Data Sources and Analysis. NOAA Technical Memorandum NESDIS NGDC-24. National Geophysical Data Centre, NOAA. doi: $10.7289 /$ V5C8276M.

Athy, L.F., 1930. Density, porosity and compaction of sedimentary rocks, Bull. Am. Assoc. Petrol. Geol., 14, 1-24.

Barton, P., 1986. Relationship between seismic velocity and density in continental crust-a useful constraint?, Geophys. J. R. astr. Soc., 87, 195-208.

Brocher, T.M., 2005. Empirical relations between elastic wave speeds and density in the Earth's crust, Bull. seism. Soc. Am., 95(6), 2081-2092.

Chen, C. et al., 2018. From continental hyperextension to seafloor spreading: new insights on the porcupine basin from wide-angle seismic data, $J$. geophys. Res.: Solid Earth, 123(10), doi:10.1029/2018JB016375.

Colombo, I., Porta, G.M., Ruffo, P. \& Guadagnini, A., 2017. Uncertainty quantification of overpressure buildup through inverse modeling of compaction processes in sedimentary basins, Hydrogeol. J., 25, 385-403.

Croker, P.F. \& Shannon, P.M., 1995. The petroleum geology of Ireland's offshore basins: introduction, Geol. Soc., Lond., Spec. Publ., 93(1), 1-8.

Eaton, B.A., 1975. The equation for geopressure prediction from well logs, in Proceedings of the Fall Meeting of the Society of Petroleum Engineers of AIME. Society of Petroleum Engineers, 28 September-1 October, Dallas, TX, pp. 1-11.

Gardner, G., Gardner, L. \& Gregory, A., 1974. Formation velocity and density — the diagnostic basics for stratigraphic traps, Geophysics, 39(6), 770-780.

Goldstein, S.L., O’Nions, R.K. \& Hamilton, P.J., 1984. A Sm-Nd isotopic study of atmospheric dusts and particulates from major river systems, Earth planet. Sci. Lett., 70(2), 221-236.

Hantschel, Th. \& Kauerauf, A.I., 2009. Fundamentals of Basin and Petroleum Systems Modeling, Springer-Verlag, pp. 467.

Hughes, S., Barton, P.J. \& Harrison, D., 1998. Exploration in the ShetlandFaeroe Basin using densely spaced arrays of ocean-bottom seismometers, Geophysics, 63, 490-501.

Jones, S.M., White, N. \& Lovell, B., 2001. Cenozoic and Cretaceous transient uplift in the Porcupine Basin and its relationship to a mantle plume, Geol. Soc., Lond., Spec. Publ., 188(1), 345-360.

Kominz, M.A., Patterson, K. \& Odette., D., 2011. Lithology dependence of porosity in slope and deep marine sediments, J. Sediment. Res., 81, 730-742.

Kominz, M.A., Miller, K.G., Browning, J.V., Katz, M.E. \& Mountain, G.S., 2016. Miocene relative sea level on the New Jersey shallow continental shelf and coastal plain derived from one dimensional backstripping: a case for both eustasy and epeirogeny, Geosphere, 12(5), 1-20.

Ludwig, W.J., Nafe, J.E. \& Drake, C.L., 1970. Seismic refraction, in The Sea, Vol. 4, pp. 53-84, ed. Maxwell, A.E., Wiley-Interscience.

Marín-Moreno, H., Minshull, T.A. \& Edwards, R.A., 2013a. A disequilibrium compaction model constrained by seismic data and application to overpressure generation in The Eastern Black Sea Basin, Basin Res., 25, 331-347.

Marín-Moreno, H., Minshull, T.A. \& Edwards, R.A., 2013b. Inverse modelling and seismic data constraints on overpressure generation by disequilibrium compaction and aquathermal pressuring: application to the Eastern Black Sea Basin, Geophys. J. Int., 194, 814-833.

McDonnell, A. \& Shannon, P.M., 2001. Comparative Tertiary stratigraphic evolution of the Porcupine and Rockall basins, Geol. Soc., Lond., Spec. Publ., 188(1), 323-344. 
Moore, J.G., 1992. A syn-rift to post-rift transition sequence in the Main Porcupine Basin, offshore western Ireland, Geol. Soc., Lond., Spec. Publ., 62(1), 333-349.

Nafe, J.E. \& Drake, C.L., 1957. Variation with depth in shallow and deep water marine sediments of porosity, density and velocities of compressional and shear waves, Geophysics, 22(3), 523-552.

Naylor, D. \& Shannon, P.M., 2011. Petroleum Geology of Ireland, Dunedin Academic Press, pp. 262.

Osborne, M.J. \& Swarbrick, R.E., 1997. Mechanisms for generating overpressure in sedimentary basins: a re-evaluation, AAPG Bull., 81(6), 10231041.

O’ Reilly, B.M., Hauser, F., Ravaut, C., Shannon, P.M. \& Readman, P.W., 2006. Crustal thinning, mantle exhumation and serpentinisation in the Porcupine Basin, offshore Ireland: evidence from wide-angle seismic data, J. geol. Soc. Lond., 163, 775-787.

Prada, M. et al., 2017. Crustal strain-dependent serpentinisation in the Porcupine Basin, offshore Ireland, Earth planet. Sci. Lett., 474, 148-159.

Prada, M., Lavoué, F., Saqab, M.M., O’Reilly, B.M., Lebedev, S., Walsh, J.J. \& Childs, C., 2018. Across-axis variations in petrophysical properties of the North Porcupine Basin, offshore Ireland: new insights from longstreamer traveltime tomography, Basin Res., 31(1), 59-76.

Ramdhan, A.M. \& Goulty, N.R., 2018. Two-step wireline log analysis of overpressure in the Bekapai Field, Lower Kutai Basin, Indonesia, Petrol. Geosci., 24, 208-217.

Reston, T.J., Gaw, V., Pennell, J., Klaeschen, D., Stubenrauch, A. \& Walker, I., 2004. Extreme crustal thinning in the south Porcupine Basin and the nature of the Porcupine Median High: implications for the formation of non-volcanic rifted margins, J. Geol. Soc., 161(5), 783-798.

Sclater, J.G. \& Christie, P.A.F., 1980. Continental stretching: an explanation of the post Mid-Cretaceous subsidence of the Central North Sea Basin, J. geophys. Res., 85, 3711-3739.

Stockwell, J.W., 1999. The CWP/SU: seismic unix package, Comput. Geosci., 25(4), 415-419.
M.S.Steckler \& A.B.Watts, 1978. Subsidence of the Atlantic-type continental margin off New York. 41(1), 1-13.

Swarbrick, R.E., Osborne, M.J. \& Yardley, G.S., 2002. Comparison of overpressure magnitude resulting from the main generating mechanisms, Proceedings of the Pressure Regimes in Sedimentary Basins and Their Prediction, Huffman, A. \& Bowers, G. AAPG Memoir 76, pp. 1-12.

Tate, M.P. \& Dobson, M.R., 1988. Syn-and post-rift igneous activity in the Porcupine Seabight Basin and adjacent continental margin W of Ireland, Geol. Soc., Lond., Spec. Publ., 39, 309-334.

Tenzer, R. \& Gladkikh, V., 2014. Assessment of density variations of marine sediments with ocean and sediment depths, Scient. World J., 2014, doi:10.1155/2014/823296.

Tingay, M.R., Hillis, R.R., Swarbrick, R.E., Morley, C.K. \& Damit, A.R., 2009. Origin of overpressure and pore-pressure prediction in the Baram province, Brunei, AAPG Bull., 93(1), 51-74.

van Ruth, P.A., Hillis, R. \& Tingate, P., 2004. The Origin of overpressure in the Carnarvon Basin, Western Australia :implications for pore pressure prediction, Petrol. Geosci., 10, 247-257.

Watremez, L. et al., 2016. Deep structure of the Porcupine Basin from wide-angle seismic data, in Proceedings of the 8th Petroleum Geology Conference. Geological Society, London, doi:10.1144/PGC8.26

Wessel, P. \& Smith, W.H., 1998. New, improved version of Generic Mapping Tools released, EOS, Trans. Am. geophys. Un., 79, 579-579.

Worthington, R.P. \& Walsh, J.J., 2016. Timing, growth and structure of a reactivated basin-bounding fault, Geol. Soc., Lond., Spec. Publ., 439, SP439-14.

Wyllie, M.R., Gregory, A.R. \& Gardner, L.W., 1956. Elastic wave velocities in heterogeneous and porous media, Geophysics, 21, 41-70.

Wyllie, M.R., Gregory, A.R. \& Gardner, L.W., 1958. An experimental investigation of factors affecting elastic wave velocities in porous media, Geophysics, 23, 459-493. 